\title{
Optimization of transparent electrode processing conditions for bulk heterojunction solar cells
}

\author{
Yechuan Sun, ${ }^{a}$ Annie Ng, ${ }^{\text {a }}$ Man Kin Fung, ${ }^{\text {A Alan Man Ching Ng, }}$ \\ Aleksandra B. Djurišić, ${ }^{a}$ and Wai Kin Chan ${ }^{\mathrm{b}}$ \\ ${ }^{a}$ University of Hong Kong, Department of Physics, Pokfulam Road, Hong Kong, China \\ keving21@hku.hk \\ ${ }^{b}$ University of Hong Kong, Department of Chemistry, Pokfulam Road, Hong Kong, China
}

\begin{abstract}
In this work, semi-transparent inverted polymer solar cells with poly(3,4-ethylenedioxythiophene):poly(styrenesulfonate; PEDOT:PSS) top electrodes were fabricated by spincoating process. Poly(3-hexylthiophene; P3HT):[6,6]-phenyl $\mathrm{C}_{61}$-butyric acid methyl ester (PCBM) was used as a model material combination for a bulk heterojunction solar cell, because this material combination has been frequently studied, and its properties and performance have been well established. For enhancing the wetting of P3HT:PCBM blend film, different plasma etching conditions were tried. In addition, different high boiling point organic additives were tried to enhance the conductivity of PEDOT:PSS. The performance of solar cells with different fabrication conditions for the top electrode was compared. The best performance was obtained for Ar plasma etching to improve wetting of PEDOT:PSS and the addition of ethylene glycol to improve conductivity. () 2012 Society of Photo-Optical Instrumentation Engineers (SPIE). [DOI: 10.1117/1.JPE.2.021005]
\end{abstract}

Keywords: bulk heterojunction solar cells; inverted solar cells; plasma treatment.

Paper 11200SS received Aug. 1, 2011; revised manuscript received Nov. 4, 2011; accepted for publication Jan. 4, 2012; published online Mar. 2, 2012.

\section{Introduction}

Low-cost bulk heterojunction solar cells have attracted much interest recently. In the development of high-efficiency bulk heterojunction solar cells, great progress has been made in the last five years with an achieved efficiency approaching $8 \% .^{1-8}$ Among different device architectures of bulk heterojunction solar cells, semi-transparent bulk heterojunction solar cells are of interest due to their potential use in window applications and tandem cells. ${ }^{9-16}$ For such applications, it is necessary to achieve a compromise between transmission and the conductivity of the transparent top electrode. By optimizing the transparent electrode, semi-transparent bulk heterojunction solar cells with good transparency and promising performance can be achieved. Although indium tin oxide is commonly used as a transparent bottom electrode for polymer solar cells, deposition of indium tin oxide (ITO) on top of the polymer layer is difficult due to the need for higher substrate temperature and damage to the polymer layer induced by deposition process, usually sputtering. Therefore, other materials such as conductive polymers are of interest. ${ }^{13-16}$

The use of PEDOT:PSS as a top electrode is promising due to its solution processing ability, which is compatible with a large scale roll-to-roll fabrication process, and mechanical flexibility which is suitable for flexible substrates. An inverted structure is often used for semi-transparent bulk heterojunction solar cells with a PEDOT:PSS top electrode because of its high work function. One of the challenges in adopting PEDOT:PSS for top electrodes is the deposition of the hydrophilic PEDOT:PSS on top of the hydrophobic photoactive layer. Many methods have been tried to overcome the wetting ability issues between the aqueous PEDOT:PSS solution and the hydrophobic photoactive layer, including doping surfactants, addition of an interfacial layer, solvent treatment, or plasma treatment on the photoactive layer, etc. ${ }^{13-17} \mathrm{O}_{2}$ plasma has been

0091-3286/2012/\$25.00 (C) 2012 SPIE 
tested as an effective way to make the surface of the photoactive layer more hydrophilic, but it could damage the surface of the photoactive layer as well ${ }^{18}$. In this work, $\mathrm{O}_{2}, \mathrm{~N}_{2}$, and Ar plasma treatment were tested and compared for the fabrication of semi-transparent inverted bulk heterojunction solar cells with a PEDOT:PSS top electrode. It was found that solar cells with $\mathrm{N}_{2}$ or $\mathrm{Ar}$ plasma treatment show better performance than those with $\mathrm{O}_{2}$ plasma treatment. Another concern with a PEDOT:PSS top electrode is low conductivity. A PEDOT:PSS film without modification usually has a conductivity less than $1 \mathrm{~S} / \mathrm{cm} .{ }^{19,20}$ Various methods to enhance the conductivity of PEDOT:PSS have been investigated. ${ }^{14-16,19-21}$ Here, a method for doping a high boiling point polar organic compound in PEDOT:PSS for enhancing the conductivity is studied and the effect of two organic compounds (EG and DMSO) are compared.

\section{Experimental Details}

\subsection{Semi-transparent Bulk Heterojunction Solar Cell Fabrication}

A titanium dioxide $\left(\mathrm{TiO}_{2}\right)$ precursor was prepared by mixing $0.229 \mathrm{ml}$ of titanium (IV) isopropoxide (TIP; 99.999\%; Sigma-Aldrich, St. Louis, MO) and $0.5 \mathrm{~g}$ of poly(ethylene glycol) (PEG; Sigma-Aldrich) in $10 \mathrm{ml}$ of isopropanol under nitrogen atmosphere. Regioregular P3HT and PCBM was purchased from American Dye Source (Baie D'Urfe, Quebec, Canada) and used as received. Fluorine doped tin oxide (FTO) coated glass was cleaned sequentially in toluene, acetone, ethanol, and deionized water, and then blown dry with nitrogen. All substrates were treated with $\mathrm{UV}$ ozone for $5 \mathrm{~min}$ prior to spin coating. $\mathrm{A} \mathrm{TiO}_{2}$ precursor was spun at $1000 \mathrm{rpm}$ for 2 min on top of the FTO as an electron-transporting layer (ETL). A stream of $\mathrm{N}_{2}$ was blown around the substrate to prevent hydrolysis of TIP when dropping the precursor. The substrate was then annealed in air at $400{ }^{\circ} \mathrm{C}$ for $1 \mathrm{~h}$. P3HT and PCBM (1:1 weight ratio) were dissolved in chlorobenzene at a concentration of $40 \mathrm{mg} / \mathrm{ml}$ and spun on top at $600 \mathrm{rpm}$ for $1 \mathrm{~min}$. Plasma treatment is performed by placing the dry samples inside a SPI Plasma Prep III Plasma Etcher (Structure Probe, Inc., West Chester, PA) with oxygen $\left(\mathrm{O}_{2}\right)$, nitrogen $\left(\mathrm{N}_{2}\right)$, or argon (Ar) introduced at $10 \mathrm{~W}$ for $10 \mathrm{sec}$. After plasma treatment, a PEDOT:PSS aqueous solution (Clevios PH 1000 ) doped with $5 \mathrm{wt} \%$ dimethyl sulfoxide (DMSO) or ethylene glycol (EG) was spun at $1000 \mathrm{rpm}$ for $2 \mathrm{~min}$ as the top electrode.

\subsection{Nontransparent Inverted Solar Cell Fabrication}

Two types of nontransparent inverted solar cells were fabricated and characterized for comparison with semi-transparent bulk-heterojunction solar cells. One type deposited gold $(\mathrm{Au})$ on top of a PEDOT:PSS film to form a nontransparent electrode. After the modified PEDOT:PSS aqueous solution was spin-cast on the plasma-treated photoactive layer, samples were transferred to an AST Peva-500EL (Hukou Shiang, Hsinchu County, Taiwan) thermal evaporation system and $60 \mathrm{~nm}$ of $\mathrm{Au}$ was thermally evaporated on top. The other type was made by replacing the PEDOT:PSS top electrode with a vanadium oxide $\left(\mathrm{V}_{2} \mathrm{O}_{5}\right) / \mathrm{Au}$ electrode. After spin-coating a P3HT:PCBM blended solution, the dried sample was transferred to the AST Peva-500EL thermal evaporation system, and a very thin $(5 \mathrm{~nm})$ layer of $\mathrm{V}_{2} \mathrm{O}_{5}$ was deposited on top as a holetransporting layer (HTL), followed by $60 \mathrm{~nm}$ of Au as the top electrode. All devices were further annealed in a $\mathrm{N}_{2}$ atmosphere at $130{ }^{\circ} \mathrm{C}$ for 5 min before current-voltage (I-V) measurement.

The I-V characterization under illumination was measured with a Keithley 2400 SourceMeter (Keithley Instruments, Inc., Cleveland, OH). A solar simulator (Oriel 66002, Newport Corporation, Irvine, CA) with an air mass 1.5 global (AM 1.5G) filter was used as the light source. The light intensity was calibrated at $100 \mathrm{~mW} / \mathrm{cm}^{2}$ by a Molectron Power Max 500D (Coherent, Inc., Santa Clara, CA) power meter. The active area for all devices was $0.0314 \mathrm{~cm}^{2}$ defined by a shadow mask.

Samples for sheet resistance measurement were fabricated by spin coating PEDOT:PSS (PH 1000 ) with and without additives (EG or DMSO) on glass at $1000 \mathrm{rpm}$ for $2 \mathrm{~min}$, followed by annealing in $\mathrm{N}_{2}$ at $130{ }^{\circ} \mathrm{C}$ for $5 \mathrm{~min}$. Sheet resistance was measured with a Keithley 2400 SourceMeter using a 4-point probe technique. 


\section{Results and Discussion}

Without plasma treatment, a PEDOT:PSS aqueous solution does not adhere well onto the active layer, which makes the resulting PEDOT:PSS top electrode layer poorly connected. This is because the surface of the P3HT:PCBM blend is highly hydrophobic. ${ }^{13,18}$ However, the adhesion of PEDOT:PSS aqueous solution is greatly improved after plasma treatment due to improved hydrophilicity of the surface of the P3HT:PCBM blend. Measurement of the contact angle before and after Ar plasma treatment indicates that a $10 \mathrm{~W}$ Ar plasma treatment for $10 \mathrm{sec}$ effectively lowered the contact angle from $92.8 \mathrm{deg}$ to $35.3 \mathrm{deg}$ (Fig. 1). The I-V characteristic of devices treated with $\mathrm{O}_{2}, \mathrm{~N}_{2}$, and Ar plasma is shown in Fig. 2. It can be seen that an $\mathrm{O}_{2}$ plasma-treated device shows a similar open circuit voltage $\left(V_{\mathrm{oc}}\right)$ to the others, but has the lowest short-circuit current density $\left(J_{\mathrm{sc}}\right)$, as well as fill factor $(\mathrm{FF})$. The $V_{\mathrm{oc}}$ of bulk heterojunction solar cells usually depends on the highest occupied molecular orbital (HOMO) of donor material (P3HT in this

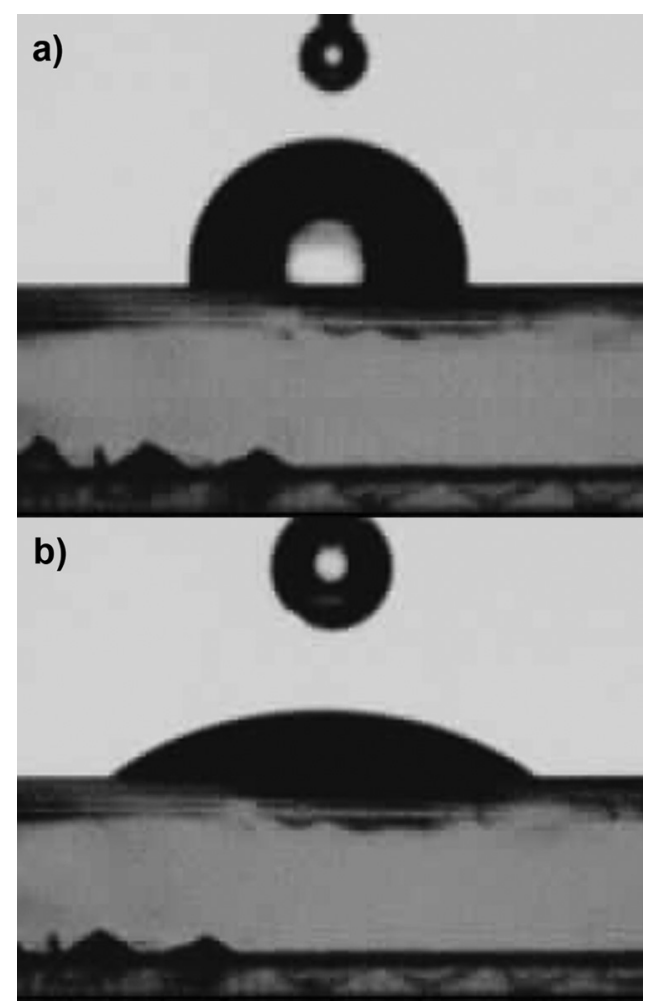

Fig. 1 Photo of water droplet on P3HT:PCBM blend surface, (a) before and (b) after Ar plasma treatment $(10 \mathrm{~W}$ for $10 \mathrm{sec})$.

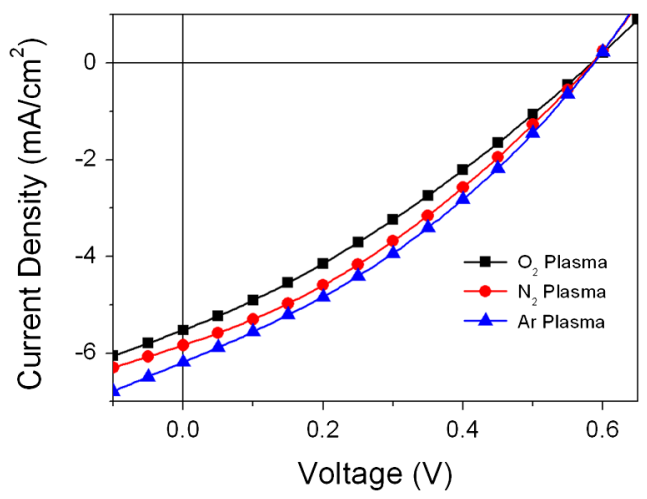

Fig. 2 I-V curves of semi-transparent bulk heterojunction solar cells using different gas $\left(\mathrm{O}_{2}, \mathrm{~N}_{2}\right.$, and $\mathrm{Ar}$ ) for plasma treatment before spin-coating PEDOT:PSS doped with 5 wt\% EG. 
Table 1 Sheet resistance of PEDOT:PSS (PH 1000) films on glass doped with different additives.

\begin{tabular}{lccr}
\hline \hline PEDOT:PSS doped with & None & 5 wt\% DMSO & 5 wt\% EG \\
\hline Sheet resistance $(\Omega / s q)$. & $1.45 \times 10^{5}$ & $1.36 \times 10^{2}$ & $1.13 \times 10^{2}$ \\
\hline \hline
\end{tabular}

Table 2 Summary of inverted bulk heterojunction solar cell performance with different fabrication conditions.

\begin{tabular}{lcccccc}
\hline \hline Top electrode & $\begin{array}{c}\text { Plasma } \\
\text { treatment }\end{array}$ & $\begin{array}{c}\text { Doped with } \\
5 \mathrm{wt} \%\end{array}$ & $v_{\mathrm{oc}}(\mathrm{V})$ & $J_{\mathrm{sc}}\left(\mathrm{mA} / \mathrm{cm}^{2}\right)$ & $\mathrm{FF}$ & $\begin{array}{c}\text { Efficiency } \\
(\%)\end{array}$ \\
\hline PEDOT:PSS (PH 1000) & $\mathrm{O}_{2}$ & $\mathrm{EG}$ & 0.59 & 5.52 & 0.30 & 0.97 \\
& $\mathrm{~N}_{2}$ & $\mathrm{EG}$ & 0.59 & 5.84 & 0.32 & 1.11 \\
& $\mathrm{Ar}$ & $\mathrm{EG}$ & 0.59 & 6.19 & 0.33 & 1.20 \\
& $\mathrm{Ar}$ & $\mathrm{DMSO}$ & 0.59 & 5.55 & 0.32 & 1.06 \\
$\mathrm{PEDOT:PSS}$ & $\mathrm{Ar}$ & $\mathrm{EG}$ & 0.60 & 8.44 & 0.41 & 2.06 \\
$(\mathrm{PH} 1000) / \mathrm{Au}$ & $\mathrm{Ar}$ & $\mathrm{DMSO}$ & 0.60 & 8.49 & 0.37 & 1.88 \\
$\mathrm{~V}_{2} \mathrm{O}_{5} / \mathrm{Au}$ & & & 0.61 & 11.07 & 0.46 & 3.12 \\
\hline \hline
\end{tabular}

case) and the lowest unoccupied molecular orbital (LUMO) of acceptor material (PCBM in this case), thus no effect on the $V_{\text {oc }}$ was observed after plasma treatment. ${ }^{22}$ The reduction in $J_{\text {sc }}$ and FF could be due to the surface oxidation of the P3HT:PCBM blend under $\mathrm{O}_{2}$ plasma. It is known that $\mathrm{O}_{2}$ plasma will react with carbon atoms in the polymer surface to form $\mathrm{C} O \mathrm{O}$ and $\mathrm{C} O \mathrm{OH}$ bonding and even affect the surface structure. ${ }^{13,23,24}$ In this study, because only a very limited power $(10 \mathrm{~W})$ in a very short time $(10 \mathrm{sec})$ was provided for the plasma treatment, no severe effect on the functionality of the P3HT:PCBM blend was observed, but it may still affect the charge transport between the P3HT:PCBM blend and the PEDOT:PSS top electrode.

Different additives have also been tried to enhance the conductivity of the PEDOT:PSS top electrode. By measuring the sheet resistance of PEDOT:PSS film on glass, it was observed that the conductivity was greatly enhanced after modification, as shown in Table 1 . From Table 2, semi-transparent solar cells using PEDOT:PSS doped with $5 \mathrm{wt} \%$ EG show a higher $J_{\text {sc }}$ and FF than those doped with DMSO. This could be due to conductivity differences between PEDOT: PSS doped with different additives and was confirmed by sheet-resistance measurement (Table 1). When comparing semi-transparent solar cells with nontransparent inverted solar cells using a $\mathrm{V}_{2} \mathrm{O}_{5} /$ Au top electrode, the latter exhibits a much higher $J_{\text {sc }}$ and FF (about double

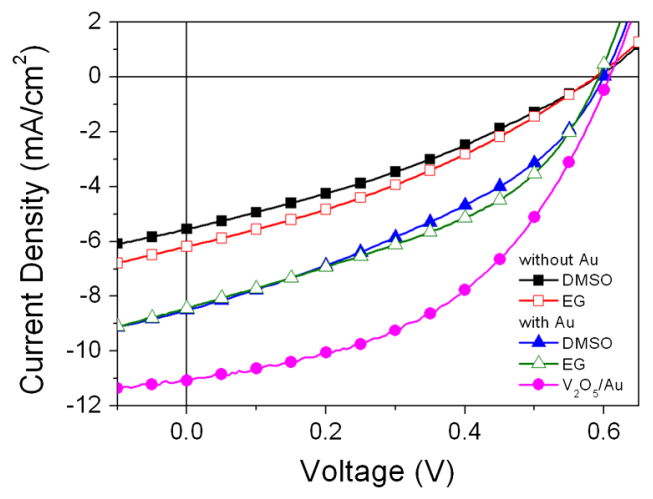

Fig. 3 I-V curves of Ar plasma-treated bulk heterojunction solar cells using PEDOT:PSS doped with different additives (5 wt\% EG and $5 \mathrm{wt} \% \mathrm{DMSO}$ ) with (triangle) and without (square) an $\mathrm{Au}$ electrode, and nontransparent inverted solar cells with a $\mathrm{V}_{2} \mathrm{O}_{5} / \mathrm{Au}$ top electrode (circle). 
in $J_{\mathrm{sc}}$ and $50 \%$ in FF). The origin could be incomplete light absorption in a semi-transparent solar cell, and inefficient charge transport between the photoactive layer and the top electrode. To better understand this phenomenon, Au was deposited on semi-transparent solar cells as a nontransparent electrode. The resulting device I-V curves are presented in Fig. 3. In this case, $J_{\mathrm{sc}}$ and FF were greatly enhanced compared with semi-transparent solar cells. In nontransparent solar cells, light can be reflected at the metal electrode, thus making the absorption in the photoactive layer better than that in the semi-transparent solar cell. The much higher conductivity of the Au electrode may also contribute to the higher FF, as well as the $J_{\text {sc }}$ in the solar cells. ${ }^{25}$

\section{Conclusion}

Semi-transparent inverted polymer solar cells were fabricated using PEDOT:PSS as the top electrode. To spin coat the hydrophilic PEDOT:PSS aqueous solution on top of the hydrophobic P3HT:PCBM surface, a mild plasma treatment using different gases was tried. Different additives for PEDOT:PSS have also been tried to increase the conductivity of the top electrode. It was found that PEDOT:PSS (PH 1000) doped with $5 \mathrm{wt} \%$ EG using a 10-W Ar plasma treatment for $10 \mathrm{sec}$ showed the best performance with an efficiency of $1.20 \%$.

\section{Acknowledgments}

This work was supported by the Strategic Research Theme, University Development Fund, and Small Project Funding of the University of Hong Kong.

\section{References}

1. M. A. Green et al., "Solar cell efficiency tables (version 38)," Prog. Photovolt: Res. Appl. 19(5), 565-572 (2011), http://dx.doi.org/10.1002/pip.1150.

2. Y. Y. Liang et al., "For the bright future-bulk heterojunction polymer solar cells with power conversion efficiency of 7.4\%," Adv. Mater. 22(20), E135-E138 (2010).

3. E. G. Wang et al., "An easily synthesized blue polymer for high-performance polymer solar cells," Adv. Mater. 22(46), 5240-5244 (2010), http://dx.doi.org/10.1002/adma.201002225.

4. S. H. Park et al., "Bulk heterojunction solar cells with internal quantum efficiency approaching 100\%," Nat. Photonics 3(5), 297-303 (2009), http://dx.doi.org/10.1038/nphoton.2009.69.

5. H. Y. Chen et al., "Polymer solar cells with enhanced open-circuit voltage and efficiency," Nat. Photonics 3(11), 649-653 (2009), http://dx.doi.org/10.1038/nphoton.2009.192.

6. J. H. Hou et al., "Synthesis, characterization, and photovoltaic properties of a low band gap polymer based on silole-containing polythiophenes and 2,1,3-benzothiadiazole," $J$. Am. Chem. Soc. 130(48), 16144-16145 (2008), http://dx.doi.org/10.1021/ja806687u.

7. J. Y. Kim et al., "Efficient tandem polymer solar cells fabricated by all-solution processing," Science 317(5835), 222-225 (2007), http://dx.doi.org/10.1126/science.1141711.

8. W. L. Ma et al., "Thermally stable, efficient polymer solar cells with nanoscale control of the interpenetrating network morphology," Adv. Funct. Mater. 15(10), 1617-1622 (2005), http://dx.doi.org/10.1002/adfm.200500211.

9. J. S. Huang, G. Li, and Y. Yang, "A semi-transparent plastic solar cell fabricated by a lamination process," Adv. Mater. 20(3), 415-419 (2008), http://dx.doi.org/10.1002/adma 200701101.

10. M. G. Kang et al., "Organic solar cells using nanoimprinted transparent metal electrodes," Adv. Mater. 20(23), 4408-4413 (2008), http://dx.doi.org/10.1002/adma.200800750.

11. H. Schmidt et al., "Efficient semitransparent inverted organic solar cells with indium tin oxide top electrode," Appl. Phys. Lett. 94(24), 243302 (2009), http://dx.doi.org/10.1063/ 1.3154556.

12. L. Shen et al., "Semitransparent polymer solar cells using $\mathrm{V}_{2} \mathrm{O}_{5} / \mathrm{Ag} / \mathrm{V}_{2} \mathrm{O}_{5}$ as transparent anodes," Org. Electron. 12(7), 1223-1226 (2011), http://dx.doi.org/10.1016/j.orgel.2011 .03 .036 . 
13. Q. F. Dong et al., "All-spin-coating vacuum-free processed semi-transparent inverted polymer solar cells with PEDOT:PSS anode and PAH-D interfacial layer," Org. Electron. 11(7), 1327-1331 (2010), http://dx.doi.org/10.1016/j.orgel.2010.04.012.

14. A. Gadisa et al., "Transparent polymer cathode for organic photovoltaic devices," Synth. Met. 156(16-17), 1102-1107 (2006), http://dx.doi.org/10.1016/j.synthmet.2006.07.006.

15. Y. H. Zhou et al., "Inverted and transparent polymer solar cells prepared with vacuum-free processing," Sol. Energ. Mater. Sol. Cell. 93(4), 497-500 (2009), http://dx.doi.org/10.1016/ j.solmat.2008.11.002.

16. T. Ameri et al., "Fabrication, optical modeling, and color characterization of semitransparent bulk-heterojunction organic solar cells in an inverted structure," Adv. Funct. Mater 20(10), 1592-1598 (2010), http://dx.doi.org/10.1002/adfm.v20:10.

17. B. Zimmermann et al., "ITO-free flexible inverted organic solar cell modules with high fill factor prepared by slot die coating," Sol. Energy Mater. Sol. Cells 95(7), 1587-1589 (2011), http://dx.doi.org/10.1016/j.solmat.2010.11.025.

18. D. Baierl et al., "Solution-processable inverted organic photodetectors using oxygen plasma treatment," Org. Electron 11(7), 1199-1206 (2010), http://dx.doi.org/10.1016/j.orgel.2010 .04 .023 .

19. S. I. Na et al., "Efficient and flexible ITO-free organic solar cells using highly conductive polymer anodes," Adv. Mater. 20(21), 4061-4067 (2008), http://dx.doi.org/10.1002/adma .200800338 .

20. Y. J. Xia, H. M. Zhang, and J. Y. Ouyang, "Highly conductive PEDOT:PSS films prepared through a treatment with zwitterions and their application in polymer photovoltaic cells," J. Mater. Chem. 20(43), 9740-9747 (2010), http://dx.doi.org/10.1039/C0JM01593H.

21. Y. H. Kim et al., "Highly conductive PEDOT:PSS electrode with optimized solvent and thermal post-treatment for ITO-free organic solar cells," Adv. Funct. Mater 21(6), 1076-1081 (2011), http://dx.doi.org/10.1002/adfm.201002290.

22. C. J. Brabec et al., "Origin of the open circuit voltage of plastic solar cells," Adv. Funct. Mater 11(5), 374-380 (2001), http://dx.doi.org/10.1002/1616-3028(200110)11:5<374:: AID-ADFM374>3.0.CO;2-W.

23. M. Mozetič, "Controlled oxidation of organic compounds in oxygen plasma," Vacuum 71(1-2), 237-240 (2003), http://dx.doi.org/10.1016/S0042-207X(02)00744-3.

24. Y. Nakamura, Y. Suzuki, and Y. Watanabe, "Effect of oxygen plasma etching on adhesion between polyimide films and metal," Thin Solid Films 290-291, 367-369 (1996), http://dx .doi.org/10.1016/S0040-6090(96)09017-7.

25. A. Manor et al., "Origin of size effect on efficiency of organic photovoltaics," J. Appl. Phys. 109(7), 074508 (2011), http://dx.doi.org/10.1063/1.3567930 